\title{
Improving the Performance of Microbial Fuel Cells with Modified Carbon Aerogel Based Cathode Catalysts
}

\author{
Bálint Lóránt ${ }^{1 *}$, Krisztina László², Gábor Márk Tardy \\ 1 Department of Applied Biotechnology and Food Science, Faculty of Chemical Technology and Biotechnology, \\ Budapest University of Technology and Economics, H-1111, Budapest, 3 Múegyetem rkp., Hungary \\ 2 Department of Physical Chemistry and Materials Science, Faculty of Chemical Technology and Biotechnology, \\ Budapest University of Technology and Economics, H-1111 Budapest, 3 Műegyetem rkp., Hungary \\ * Corresponding author, e-mail: Iorant.balint@edu.bme.hu
}

Received: 29 June 2021, Accepted: 19 August 2021, Published online: 19 November 2021

\begin{abstract}
Microbial fuel cells (MFCs) are capable of converting the chemical energy of biodegradable organic matter directly into electricity, thus they can be applied in various fields: waste elimination, biosensor industry and production of renewable energy. In this study, the efficiency of noble metal free carbon aerogel based cathode catalysts was investigated and compared to plain glassy carbon cloth without catalyst (CC) and platinum containing carbon powder catalyst (PtC) in H-type MFCs. Surface extension by carbon aerogel (CA) enhanced the maximum power density by $34 \%$ compared to CC, to $14.1 \mathrm{~W} \mathrm{~m}^{-3}$. With nitrogen doped carbon aerogel (NCA) the performance was further increased to $15.7 \mathrm{~W} \mathrm{~m}^{-3}$. Co-doping the resorcinol-melamine-formaldehyde based aerogel with graphene oxide (GNCA) resulted in an additional power increase of $70 \%$, indicating that the electrocatalytic activity of NCAs can be considerably improved by co-doping with graphene oxide. Although the performance of GNCA remained below that of PtC $\left(50.2 \mathrm{~W} \mathrm{~m}^{-3}\right)$ in our investigations, it can be concluded that GNCA based coatings may provide a noble metal free, and therefore competitive and sustainable alternatives for cathode catalysis in MFC based technologies.
\end{abstract}

\section{Keywords}

microbial fuel cell, nitrogen doped carbon aerogels, graphene oxide

\section{Introduction}

In microbial fuel cells (MFCs) a specific bacterial consortium of the so-called exoelectrogenic bacteria produces electricity directly from the biodegradation of organic substrates $[1,2]$. The layout of MFCs is similar to that of chemical fuel cells, but in this case, the anodic compartment operates as a bioreactor. The exoelectrogenic biomass forms biofilm on the anode and via the biodegradation of organic compounds, these bacteria transport electrons to the electrode, producing voltage and current in the external circuit (potentially renewable electricity) [3]. The anodic compartment of the cell is generally separated from the cathode by a cation exchange membrane (CEM, e.g. proton selective ion-exchange membrane, such as Nafion $\left.{ }^{\circledR}\right)$. Through the CEM, cations (including protons as well) are transported into the catholyte, meanwhile oxygen is reduced to water on the surface of the cathode by the electrons arriving through the external circuit [4].
The research and development of the application of MFCs has grown exponentially in the last decades with promising results. MFCs can be used as power sources producing renewable energy, although the relatively low voltage and power limit the applicability of this technology. Thus, electric devices only with low power requirement can be supplied with MFCs. At the same time, charging of specific energy storage devices (accumulators, capacitors) can be an option [5]. High are the expectations for the applicability of MFCs in the field of environmental protection, as MFC based efficient wastewater treatment and waste elimination technologies are under development with considerably lower energy requirement than the currently applied conventional technologies. In addition, organic pollutant elimination in MFCs generates a decent amount of electricity as well $[6,7]$. The third main field of application of MFCs is in the biosensor industry: the rate of the biological process in the anodic compartment 
is in direct connection with the electric parameters (voltage, current, total charge) measured in the cell. As a result, the aforementioned electric parameters may refer to the quality, concentration and possibly to the composition of biodegradable organics in the anolyte of the MFC. Specialized MFC based biosensors have been developed for different purposes: environmental analysis, for application in healthcare, etc. [8-10].

Besides the rate of the anodic processes carried out by the exoelectrogenic biomass, the efficiency of the oxygen reduction reaction (ORR) on the cathode is a key element determining the performance (e.g. the power output) of this technology. The most frequently applied cathode material is carbon (e.g. graphite, activated carbon), but the rate of ORR on the surface of plain carbon is rather low. To enhance the ORR, generally catalysts are applied. The most well-known, conventional ORR catalyst is platinum $[11,12]$. The high cost of this material, however, is a great barrier of the implementation of full-scale MFC based technologies, so the development of alternative catalysts is crucial to facilitate real-life applications of MFC systems. As a result, several researches aimed to develop noble metal free catalysts to decrease the material cost and make the technology more competitive and sustainable.

Providing large specific surface area for the ORR, carbon aerogels might be promising base materials for MFC cathodes. Doping the carbon base material with heteroatoms $(\mathrm{N}, \mathrm{P}, \mathrm{S})$ may considerably enhance the performance of the cathode, due to the doping-induced charge redistribution, which can facilitate the chemisorption of $\mathrm{O}_{2}$ and the electron transfer for the ORR process [13, 14]. In our previous publication [15], the application of a nitrogen doped carbon aerogel (NCA) as cathode catalyst was investigated and evaluated in H-type MFCs, concluding that the performance of the plain graphite felt cathode can be enhanced by $170 \%$ by coating it with this catalyst, and as a result the cell's power density reached a value of $37 \mathrm{~W} \mathrm{~m}^{-3}$. In the past five years, several researchers developed various carbon aerogels with nitrogen content for cathode catalysis. Yang et al. [16] reached the performance of a Pt based cathode catalyst by applying high graphitic-N concentration (5\%), Zhang et al. [17] outperformed Pt/C catalyst by $48 \%$ using carbon aerogels with extra high surface area $\left(1535 \mathrm{~m}^{2} \mathrm{~g}^{-1}\right)$ and pore volume $\left(2.43 \mathrm{~m}^{3} \mathrm{~g}^{-1}\right)$. Tian et al. [18] demonstrated in single chamber MFCs that pre-treatment of carbon aerogels with $\mathrm{KOH}$ may further enhance the efficiency of these catalysts by activating and increasing the surface area.
Due to their excellent electronic properties, the application of nanocarbon materials such as carbon nanotubes and graphene oxide as electrodes in bioelectrochemical systems have gained also high interest [13]. Graphene oxide supported zinc, cobalt and calcium oxides proved to be efficient cathode materials in MFCs [19, 20]. It was found that the electrocatalytic efficiency of nitrogen doped carbon aerogels can be further enhanced by co-doping with graphene oxide [21]. Earlier works demonstrated that incorporation of graphene oxide significantly enhances the electrical conductivity of aerogels [22]. In the present research, three carbon aerogels with various composition:

1. a resorcinol-formaldehyde aerogel (CA),

2. a resorcinol-melamine-formaldehyde (NCA) and

3. an NCA co-doped with graphene oxide (GNCA) were applied as cathode catalyst in a dual-chamber MFC to compare and evaluate the efficiency and to determine the effect of nitrogen and graphene oxide on the performance of the cathode.

\section{Materials and methods \\ 2.1 MFC configuration}

Two identical H-type MFCs (MFC-A and MFC-B) were constructed using $330 \mathrm{~mL}$ glass bottles, serving as anode and cathode chambers described before in details [23]. The two chambers were connected by a glass tube, holding the proton exchange membrane (Nafion, NRE-212, $0.05 \mathrm{~mm}$, Alfa Aesar). The arrangement provided $7.2 \mathrm{~cm}^{2}$ free membrane surface for proton transfer. The anode chamber was stirred by magnetic stirrers. Temperature of the systems was maintained at $30^{\circ} \mathrm{C}$ using a thermostat. $3.1 \mathrm{~cm} \times 2.5 \mathrm{~cm} \times 0.9 \mathrm{~cm}$ rectangular graphite felt (Zoltek, Hungary) was applied as anode, fixed on a stainless steel wire for electric connection with the circuit. 0-2000 $\Omega$ helipot was used as adjustable external resistor. Voltage was measured and registered by a Graphtec midi logger GL840 oscilloscope.

Glassy carbon cloth was used as base material for cathodes. Catalytic efficiency of the three different carbon aerogels was evaluated by comparing the performance of cathodes coated with these catalysts. A catalyst-free glassy carbon cloth cathode and a cathode coated with conventional platinum catalyst were used as reference electrodes. Thus, five cathode types were prepared (Table 1). Each type was created in two sizes: $6 \mathrm{~cm} \times 6 \mathrm{~cm}$ (surface area of $72 \mathrm{~cm}^{2}$, as both sides were coated) and $6 \mathrm{~cm} \times 2 \mathrm{~cm}\left(24 \mathrm{~cm}^{2}\right)$. As the thickness of the glassy carbon cloth was $<0.3 \mathrm{~mm}$, it was considered to be two dimensional. 
Since the applied catalysts had different specific surface areas, the amounts used for the coating process were different to ensure that every cathode type has the same active surface area, as the goal of the research was to investigate the effect of the presence of nitrogen heteroatoms and graphene oxide on the catalyst performance. Thus, each coated $6 \mathrm{~cm} \times 6 \mathrm{~cm}$ electrode provided $117 \mathrm{~m}^{2}$, while $6 \mathrm{~cm} \times 2 \mathrm{~cm}$ cathodes provided $39 \mathrm{~m}^{2}$ active catalyst surface area (see Table 1.). Coating was carried out by fixing the catalysts on the surface of the glassy carbon cloth with Nafion ${ }^{\circledR}$ ( $5 \%$ solution, Alfa Aesar), based on our previous publication [15].

\subsection{Preparation and characterization of cathode catalysts}

As received, glassy carbon cloth (CC) was used as reference cathode without any modification. Platinum containing reference cathode $(\mathrm{PtC})$ was prepared by fixing $\mathrm{Pt} / \mathrm{C}\left(10 \mathrm{w} / \mathrm{w} \%, 880 \mathrm{~m}^{2} \mathrm{~g}^{-1}\right.$, Alfa Aesar) on the surface of the glassy carbon cloth. The three investigated carbon aerogels of different composition and surface morphology were prepared as follows:

1. The precursor of the resorcinol (R) - formaldehyde $(\mathrm{F})$ polymer based carbon aerogel (CA) was obtained from the aqueous polycondensation reaction according to the method proposed by Lin and Ritter [24]. The overall concentration of the aqueous solution was $5 \mathrm{wt} \%$ by setting the molar ratios as $\mathrm{R} / \mathrm{F}=0.5$ and $\mathrm{R} / \mathrm{Na}_{2} \mathrm{CO}_{3}=50$. The hydrogel was obtained after 1 week polymerization at $85^{\circ} \mathrm{C}$. After solvent exchange, the polymer aerogel was dried with supercritical $\mathrm{CO}_{2}$. The $\mathrm{CA}$ was prepared by carbonization in dry $\mathrm{N}_{2}$ atmosphere at $900^{\circ} \mathrm{C}$ [25].

2. The nitrogen doped carbon aerogel (NCA) was obtained similarly, but melamine (M) was also added to the precursor solution. The molar ratios were $\mathrm{M} / \mathrm{R}=0.2, \mathrm{R} \mathrm{Na}_{2} \mathrm{CO}_{3}=50, \mathrm{~F}=(2 \mathrm{R}+3 \mathrm{M})$. Further steps of the synthesis are the same as in case of CA. All the chemicals were purchased from Merck.

3. The third sample was prepared similarly to NCA, but graphene oxide $(\mathrm{GO})$ suspension was also added to the precursor solution based on [22]. The GO/R mass ratio was 0.1 . The GO suspension was made in our laboratory from a natural graphite (Graphite, Tyn, Czechia).

Low-temperature $\left(-196{ }^{\circ} \mathrm{C}\right)$ nitrogen adsorption isotherms were measured with a NOVA 2000e automatic analyzer (Quantachrome). The apparent surface area $S_{\mathrm{BET}}$ was calculated using the Brunauer-Emmett-Teller (BET) model [26]. The total pore volume $\left(V_{\text {tot }}\right)$ was estimated from the amount of nitrogen adsorbed at relative pressure $p / p_{0}=0.95$ assuming that the pores were then filled with a liquid adsorbate. The micropore volume was derived from the Dubinin-Radushkevich (DR) plot [27]. Pore size distributions were calculated by the quenched solid state density functional theory (QSDFT) model [28]. The best fit was obtained with the kernel for cylinder/sphere pore geometry. The transformation of all the primary adsorption data was performed by the Quantachrome software ASiQwin version 3.0.

\subsection{Electrolyte composition, inoculation, operation of the MFC}

Electrolyte salt solution applied in the anode and cathode chamber was the same, containing:

- $3.13 \mathrm{~g} \mathrm{NaHCO}_{3}$,

- $0.31 \mathrm{~g} \mathrm{NH}_{4} \mathrm{Cl}$,

- $0.13 \mathrm{~g} \mathrm{KCl}$,

- $4.22 \mathrm{~g} \mathrm{NaH}_{2} \mathrm{PO}_{4}$,

- $6.93 \mathrm{~g} \mathrm{Na}_{2} \mathrm{HPO}_{4} \times 12 \mathrm{H}_{2} \mathrm{O}$, plus trace elements, in $1 \mathrm{~L}$ based on our previous works [15, 29, 30].

Table 1 Applied catalysts, cathode types, and sizes (large cathode - L, small cathode - S)

\begin{tabular}{|c|c|c|c|c|c|}
\hline Cathode sign & Catalyst & $\begin{array}{l}\text { Specific surface area } \\
\text { of the catalyst }\left(\mathrm{m}^{2} \mathrm{~g}^{-1}\right)\end{array}$ & Cathode size $(\mathrm{cm} \times \mathrm{cm})$ & $\begin{array}{l}\text { Catalyst coating } \\
\text { amount }(\mathrm{g})\end{array}$ & $\begin{array}{l}\text { Total catalyst surface } \\
\text { area on the cathode }\left(\mathrm{m}^{2}\right)\end{array}$ \\
\hline \multirow{2}{*}{$\mathrm{CC}$} & \multirow{2}{*}{$\begin{array}{l}\text { no catalyst, plain glassy } \\
\text { carbon cloth }\end{array}$} & \multirow{2}{*}{-} & $6 \times 6 \quad L$ & - & - \\
\hline & & & $6 \times 2 \mathrm{~s}$ & - & - \\
\hline \multirow{2}{*}{ CA } & \multirow{2}{*}{ carbon aerogel } & \multirow{2}{*}{687} & $6 \times 6 \mathrm{~L}$ & 0.170 & 117 \\
\hline & & & $6 \times 2 \mathrm{~S}$ & 0.057 & 39 \\
\hline \multirow{2}{*}{ NCA } & \multirow{2}{*}{$\begin{array}{l}\text { nitrogen-doped carbon } \\
\text { aerogel }\end{array}$} & \multirow{2}{*}{117} & $6 \times 6 \quad L$ & 1.000 & 117 \\
\hline & & & $6 \times 2 \mathrm{~S}$ & 0.333 & 39 \\
\hline \multirow{2}{*}{ GNCA } & \multirow{2}{*}{$\begin{array}{l}\text { nitrogen and graphene oxide } \\
\text { doped carbon aerogel }\end{array}$} & \multirow{2}{*}{234} & $6 \times 6 \quad L$ & 0.500 & 117 \\
\hline & & & $6 \times 2 \mathrm{~S}$ & 0.166 & 39 \\
\hline \multirow{2}{*}{$\mathrm{PtC}$} & \multirow{2}{*}{$\begin{array}{l}\text { platinum containing carbon } \\
\text { powder }\end{array}$} & \multirow{2}{*}{880} & $6 \times 6 \quad L$ & 0.133 & 117 \\
\hline & & & $6 \times 2 \mathrm{~S}$ & 0.044 & 39 \\
\hline
\end{tabular}


Standard anolyte media was prepared by supplementing the basic salt solution with $50 \mathrm{mmol} \mathrm{L}^{-1}$ sodium acetate (Molar Chemicals) as organic substrate.

Primary sludge originated from a domestic wastewater treatment plant was used as inoculum. Before introducing to the anode chamber, the raw sludge was filtered through a $0.5 \mathrm{~mm}$ hole size hand sieve and diluted to $\sim 1 \mathrm{~g} \mathrm{TSS} \mathrm{L}^{-1}$ (total suspended solids) by the anolyte. The voltage raised and stabilized in a $\sim 15$ days long startup phase. Having the voltage stabilized, the inoculating suspension was washed out from the anode chamber with fresh media. The fresh media was de-oxygenated by heating it up to $\sim 70{ }^{\circ} \mathrm{C}$, and at the same time sparging with $\mathrm{N}_{2}$ for 10 minutes to ensure the anaerobic conditions.

Anolyte was washed out and replaced by fresh de-oxygenated media containing $50 \mathrm{mmol} \mathrm{L}^{-1}$ sodium acetate every week during the experiment to avoid substrate depletion. In standard operation, $1000 \Omega$ of external resistance was applied, except during polarization tests.

\subsection{Polarization tests}

After the inoculation and the startup period, performance of the different cathodes (CC, CA, NCA, GNCA, PtC) (see Table 1) was investigated in both MFC-A and MFC-B by polarization experiments. Having a new cathode placed into the cathode chamber, a 24 hours long stabilization period was necessary to get a stable voltage before the polarization. Having the voltage stabilized, polarization measurement was carried out.

To eliminate the effect of a possible hysteresis, polarization tests were carried out by increasing the external resistance from 0 to $2000 \Omega$ in specified steps, after that, decreasing the resistance from 2000 to $0 \Omega$ using the same steps. Polarization curves were obtained by calculating the averages of the two voltage data measured for each external resistance value. Current, power and internal resistance data were calculated from the voltage values.

\section{Results and discussion}

Nitrogen adsorption isotherms were used to reveal the textural differences of the samples. The differential and integral pore size distribution curves (Fig. 1(A) and (B)) reveal the significantly different porous character of the samples. The low surface area of the NCA carbon is combined with a limited pore volume. The average pore size hardly exceeds the size of micropores [31]. The CA sample has the largest pore volume, but the detected pore size does not exceed $20 \mathrm{~nm}$. The GNCA carbon possesses a

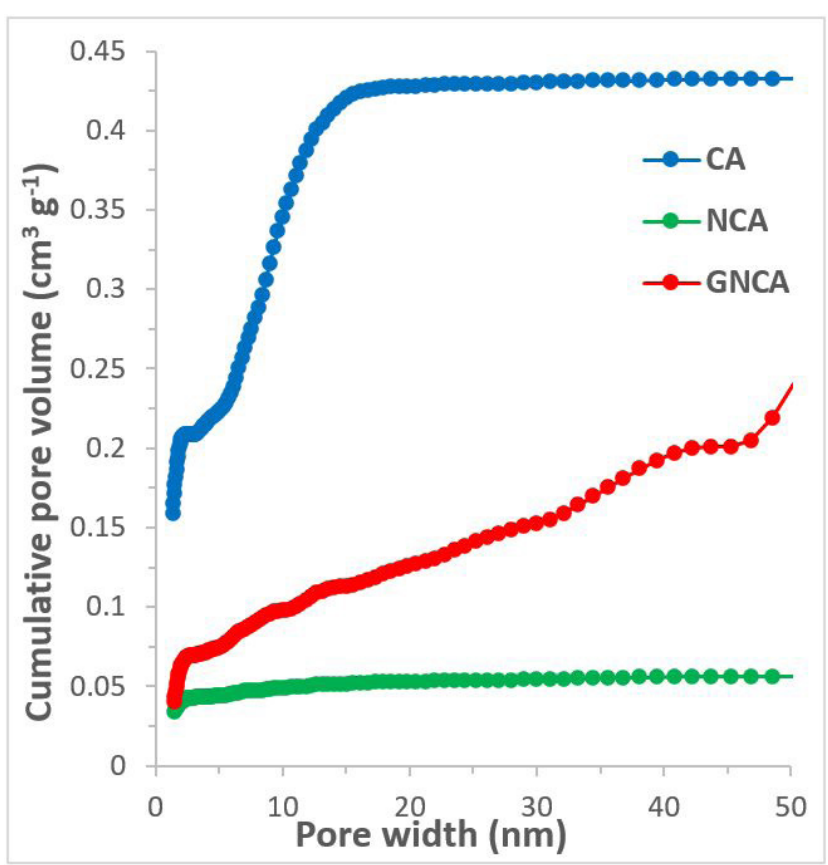

(A)

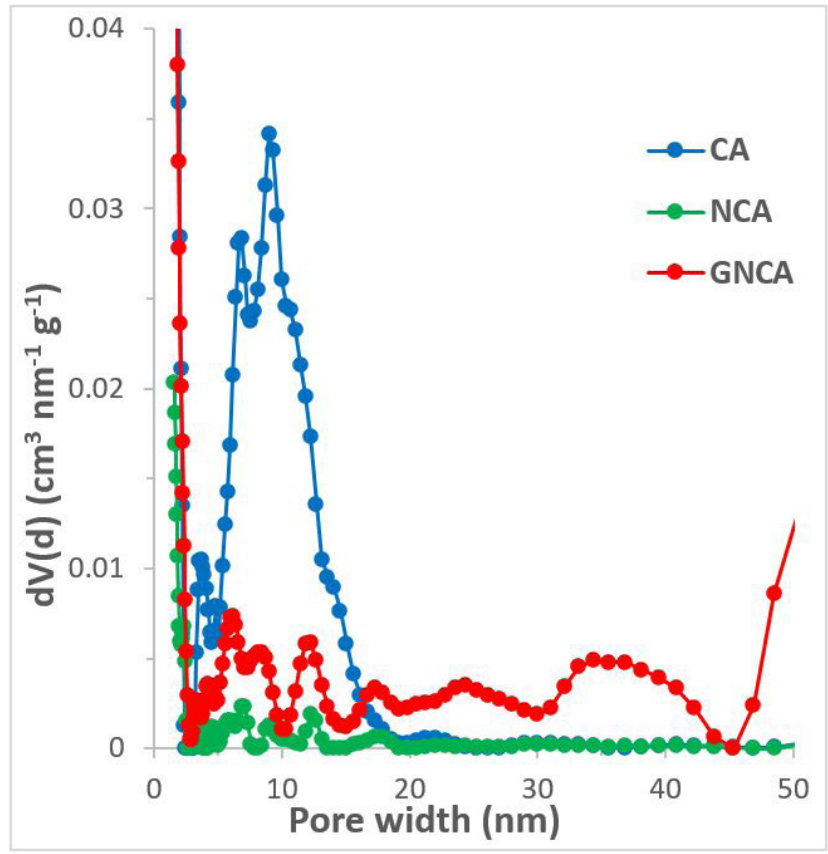

(B)

Fig. 1 Integral (A) and differential (B) pore size distribution of the three carbon aerogels calculated from the quenched solid state density functional theory (QSDFT)

wide pore size distribution, going well beyond the other two aerogels. The more open pore texture is also reflected by the lowest contribution of the micropores (only $31 \%$ ) and the widest average pore size $d_{\text {ave }}$ (Table 2).

Typical polarization curves obtained in MFC-A with the $6 \times 6 \mathrm{~cm}$ (large) cathodes are depicted in Fig. 2. As the 
Table 2 Specific surface area and pore size characteristics of the investigated carbon aerogels

\begin{tabular}{lccccc}
\hline Sample & $\begin{array}{c}S_{\mathrm{BET}} \\
\mathrm{m}^{2} \mathrm{~g}^{-1}\end{array}$ & $\begin{array}{c}V_{\text {tot }} \\
\mathrm{cm}^{3} \mathrm{~g}^{-1}\end{array}$ & $\begin{array}{c}V_{\text {micro }} \\
\mathrm{cm}^{3} \mathrm{~g}^{-1}\end{array}$ & $V_{\text {micro }} / V_{\text {tot }}$ & $\begin{array}{c}d_{\text {ave }}{ }^{*} \\
\mathrm{~nm}\end{array}$ \\
\hline $\mathrm{CA}$ & 687 & 0.455 & 0.267 & 0.59 & 2.65 \\
$\mathrm{NCA}$ & 117 & 0.061 & 0.047 & 0.77 & 2.09 \\
GNCA & 234 & 0.303 & 0.093 & 0.31 & 5.16 \\
\hline
\end{tabular}

"calculated as $4 V_{\text {tot }} / S_{\text {BET }}$
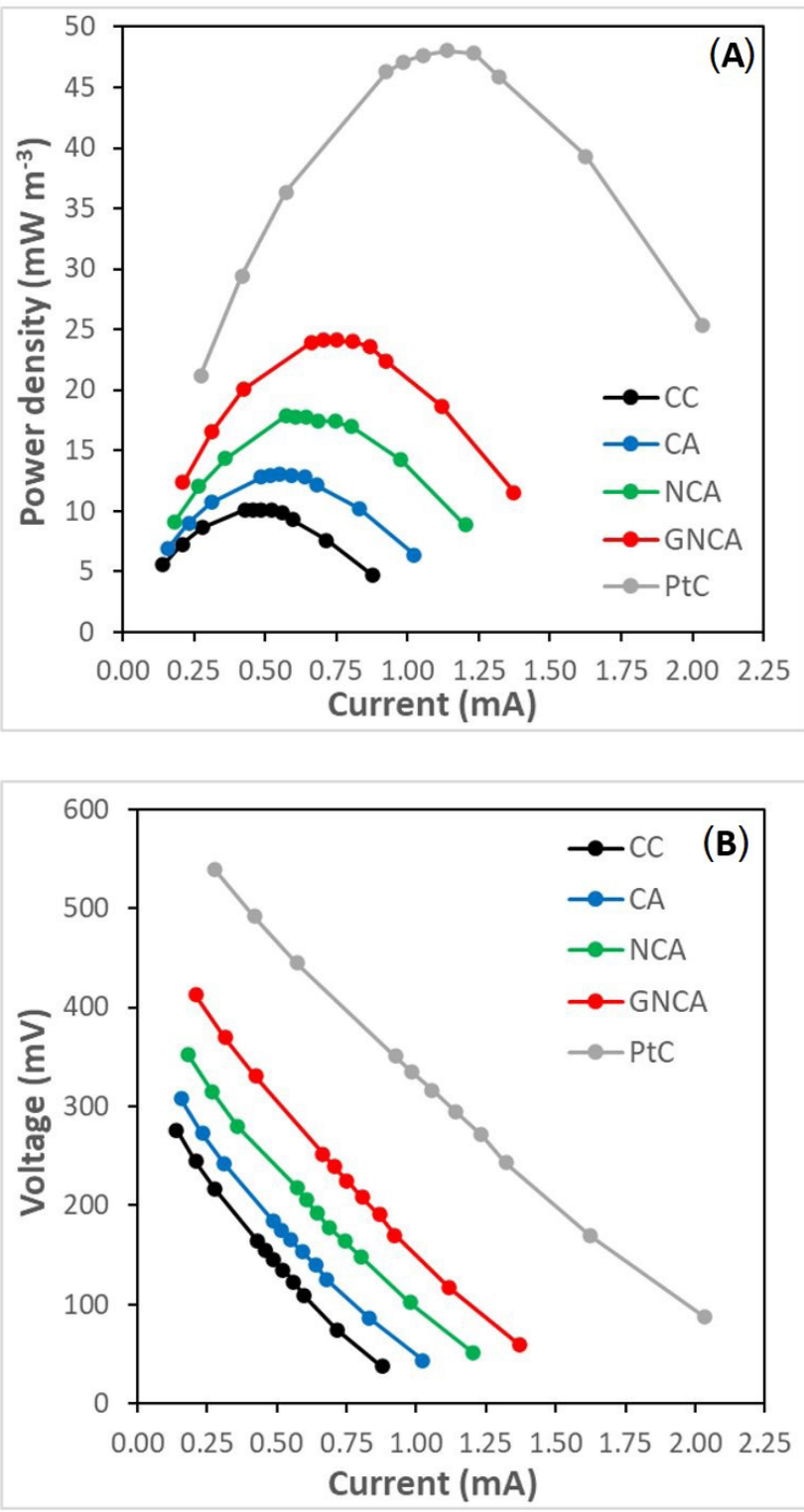

Fig. 2 Polarization curves obtained in MFC-A with $6 \times 6 \mathrm{~cm}$ cathodes; (A) Power densities vs current; (B) Voltage values vs current

graphite felt had a discrete thickness of $0.9 \mathrm{~cm}$ giving a cuboid shape to the anode, the power density values were normalized to the volume $\left(7 \mathrm{~cm}^{3}\right)$ of the anode, resulting in $\mathrm{W} \mathrm{m}^{-3}$ dimension, similarly to our previous work [15]. The application of carbon aerogel coated cathodes enhanced the performance of the MFC compared to the plain carbon cloth cathode (CC) with all the applied external resistance values during the polarization. Comparing to the values obtained with $\mathrm{CC}$, by applying $\mathrm{CA}$ increased the power density by $30 \%$ in average, meanwhile by using NCA the average increment was $\sim 80 \%$. Incorporating graphene (GNCA) resulted in further enhancement of the performance by $130 \%$ increase in the power density in average, compared to CC. However, similarly to our previous research [15], the highest power densities were reached with the PtC catalyst, providing 4.7 times higher values than the CC. In order to verify this result and to collect appropriate amount of data for the calculation of standard deviation, at least five polarization curves were measured with each type and size of cathodes. During statistical data analysis, the significance level $(\alpha)$ was 0.05 .

Maximum power density $\left(P_{\text {DAmax }}\right)$ and internal resistance $\left(R_{\text {int }}\right)$ values calculated from the polarization experiments are depicted in Fig. 3. for MFC-A and MFC-B with the two different cathode sizes. For both $P_{\text {DAmax }}$ and $R_{\text {int }}$, the two MFCs provided practically the same values, no significant differences were found between the two cells, indicating that the measurement were appropriately reproducible.

$10.5 \mathrm{~W} \mathrm{~m}^{-3}$ average $P_{\text {DAmax }}$ was obtained with $6 \times 6 \mathrm{~cm}$ CC cathodes (see Fig. 3(A)). By applying CA cathode, $P_{\text {DAmax }}$ increased to $14.1 \mathrm{~W} \mathrm{~m}^{-3}$ and the difference between $\mathrm{CC}$ and $\mathrm{CA}$ is significant, indicating that the additional reaction surface area enhanced the ORR. NCA provided higher power density $\left(15.7 \mathrm{~W} \mathrm{~m}^{-3}\right)$, suggesting that the presence of nitrogen heteroatoms fosters the ORR, however the difference between CA and NCA lagged behind what was expected, as previous experiments showed that $\mathrm{N}$ might have a more positive impact on ORR [15].

This finding may be attributed to the substantially dissimilar morphological features of CA and NCA. As the difference in specific surface area values was compensated by the amount of catalyst used for coating (see Table 1), this finding verifies that the previously discussed differences in the porous structure play also an important role in the electrode process, as described before [21, 32]. The exclusively microporous texture of the NCA is less favorable for ORR: the transport processes are certainly limited within the narrow pores.

Applying GNCA, $P_{\text {DAmax }}$ raised to 22.0 and $23.2 \mathrm{~W} \mathrm{~m}^{-3}$ (see Fig. 3(A)), resulting in significant improvement and 104 and $110 \%$ increase compared to the values obtained with CC in MFC-A and MFC-B, respectively, verifying the 

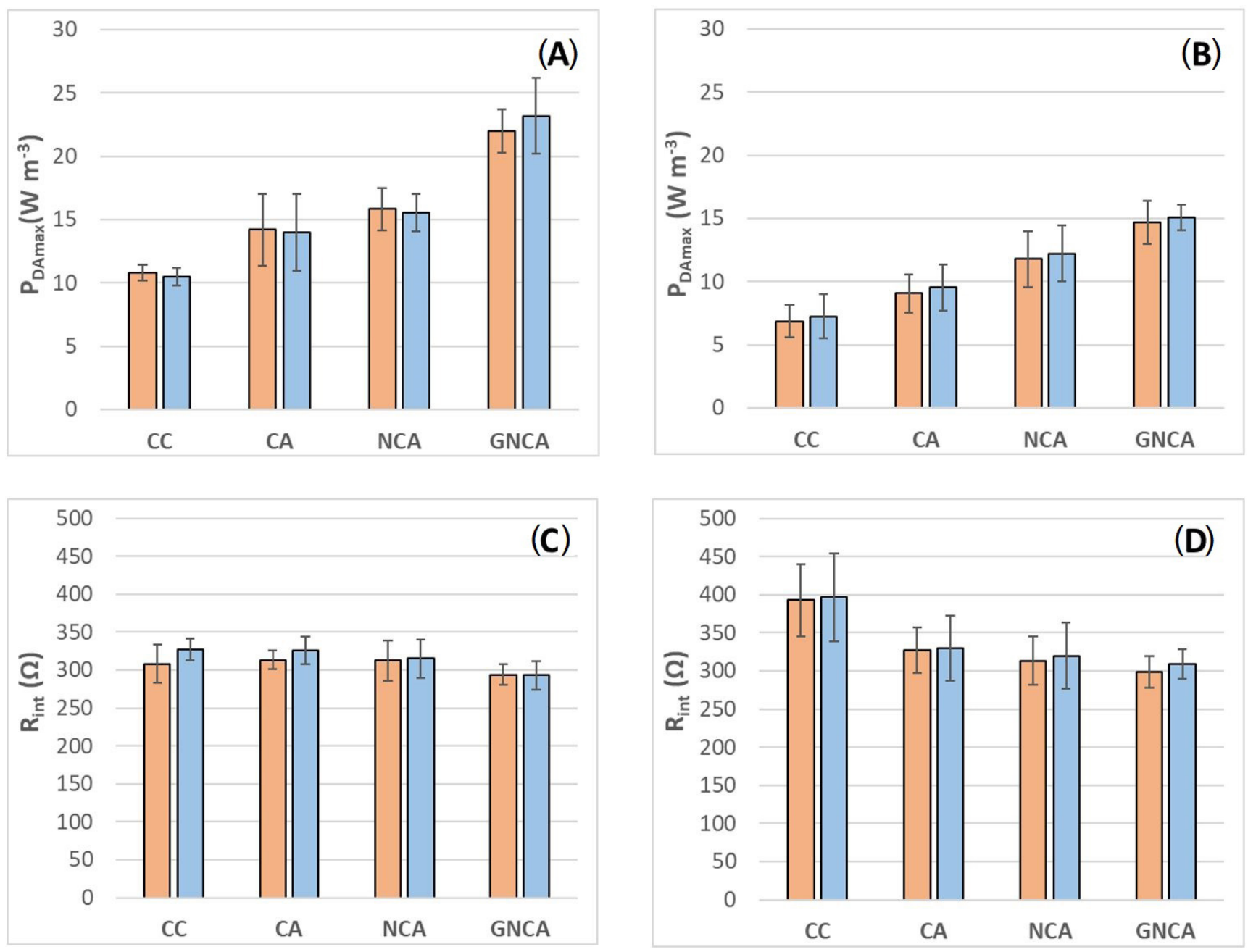

Fig. 3 Maximum power density normalized to anode volume $\left(\mathrm{P}_{\mathrm{DAmax}}\right)$; (A) with $6 \times 6 \mathrm{~cm}$ cathodes; (B) with $6 \times 2 \mathrm{~cm}$ cathode; and internal resistance $\left(\mathrm{R}_{\text {int }}\right) ;(\mathrm{C})$ with $6 \times 6 \mathrm{~cm}$ cathode; (D) with $6 \times 2 \mathrm{~cm}$ cathode - in MFC-A (red) and MFC-B (blue)

positive contribution of the graphene oxide derivative in the ORR, partly attributed to the more open pore structure of this carbon sample. Highest, $50.2 \mathrm{~W} \mathrm{~m}^{-3} P_{\mathrm{DAmax}}$ value was obtained by applying PtC (not depicted in Fig. 3).

While the positive effect of the different catalysts on the power of the MFCs is obvious, no substantial differences were observed in the internal resistance values (see Fig. 3(C)): all the tested carbon aerogel cathodes (CA, NCA, GNCA) resulted in average $R_{\text {int }}$ values between 290 and $325 \Omega$ similarly to $R_{\text {int }}$ value of CC. It suggests, that although the ORR rate is enhanced by the catalysts, the potential losses on the carbon aerogel catalyzed cathodes were practically the same as with CC. At the same time, PtC provided a slightly lower $R_{\text {int }}$ value: 243 and $258 \Omega$ for MFC-A and MFC-B, respectively.

Reducing the cathode surface from $72 \mathrm{~cm}^{2}(6 \times 6 \mathrm{~cm}$ cathodes) to $24 \mathrm{~cm}^{2}(6 \times 2 \mathrm{~cm}$ cathodes) considerably decreased the $P_{\text {DAmax }}$ values (see Fig. 3(B)), but the trend in the average values $(\mathrm{CC}<\mathrm{CA}<\mathrm{NCA}<\mathrm{GNCA})$ was the same as with $6 \times 6 \mathrm{~cm}$ cathodes, verifying that besides the presence of nitrogen, GO can further enhance the cathode ORR efficiency, independently from the reaction surface.

Decreasing the cathode surface from 72 to $24 \mathrm{~cm}^{2}$ resulted in the significant raise of internal resistance values in case of CC cathodes (from 328 and $327 \Omega$ to 393 and $397 \Omega$ averages for MFC-A and MFC-B, respectively). By applying CA, NCA and GNCA, no significant increment was observable, average $R_{\text {int }}$ values remained in the 295-330 $\Omega$ range, suggesting that the application of these catalysts may partly compensate the negative effect of the reduced cathode size.

It has to be pointed out, that although the available surface of the cathode decreased to one third of its original size, $P_{\text {DAmax }}$ values decreased only by $\sim 30 \%$. To compare the cathode-specific performance of the cells with the two different cathode sizes, maximum power densities 
normalized to the geometric surface (72 and $24 \mathrm{~cm}^{2}$ ) of the cathodes were calculated $\left(P_{\mathrm{DC} \max }\right.$, see Fig. 4). $P_{\text {DCmax }}$ values obtained with $6 \times 6 \mathrm{~cm}$ cathodes provided $10-23 \mathrm{~W} \mathrm{~m}^{-2}$ with the investigated cathodes, except for $\mathrm{PtC}$ (48.5 $\mathrm{W} \mathrm{m}^{-2}$, not depicted in Fig. 4). Using the electrodes with the reduced surface area, $P_{\mathrm{DCmax}}$ values considerably increased (approximately doubled) for all cases. It suggests that depending on the anodic (biological) performance of the cell, these cathodes may flexibly provide higher surface-specific ORR rates.

\section{Conclusions}

Carbon aerogel based coatings proved to be efficient cathode catalysts in H-type microbial fuel cells. Applying cathodes with $72 \mathrm{~cm}^{2}$ surface area, $10.5 \mathrm{~W} \mathrm{~m}^{-3}$ average $P_{\text {DAmax }}$ values were obtained by using $\mathrm{CC}$, that raised to 14.1 and $15.7 \mathrm{~W} \mathrm{~m}^{-3}$ with CA and NCA, respectively. With GNCA, the performance further increased significantly, up to $22.6 \mathrm{~W} \mathrm{~m}^{-3}$ in average in the two investigated cells. It means that co-doping of graphene with nitrogen resulted in additional $70 \%$ power increase in the MFCs compared to NCA (more than $130 \%$ total increase compared to CC). Higher catalytic capability of GNCA is partly attributed to the more open pore structure of this carbon sample. Based on these results, it can be suggested that the electrocatalytic activity of resorcinol-melamine-formaldehyde originated nitrogen doped aerogels can be considerably improved by co-doping them with graphene oxide.

Although the performance of GNCA remained below $\mathrm{PtC}\left(50.2 \mathrm{~W} \mathrm{~m}^{-3}\right)$ in our investigations, it can be concluded that GNCA-based coating may provide a cheaper, noble

\section{References}

[1] Flimban, S. G. A., Ismail, I. M. I., Kim, T., Oh, S. E. "Overview of Recent Advancements in the Microbial Fuel Cell from Fundamentals to Applications: Design, Major Elements, and Scalability", Energies, 12(17), Article number: 3390, 2019. https://doi.org/10.3390/en12173390

[2] Cao, Y., Mu, H., Liu, W., Zhang, R., Guo, J., Xian, M., Liu, H. "Electricigens in the anode of microbial fuel cells: pure cultures versus mixed communities", Microbial Cell Factories, 18(1), Article number: 39, 2019. https://doi.org/10.1186/s12934-019-1087-z

[3] Rabaey, K., Verstraete, W. "Microbial fuel cells: novel biotechnology for energy generation", Trends in Biotechnology, 23(6), pp. 291-298, 2005.

https://doi.org/10.1016/j.tibtech.2005.04.008

[4] Oliot, M., Galier, S., Roux de Balmann, H., Bergel, A. "Ion transport in microbial fuel cells: Key roles, theory and critical review", Applied Energy, 183, pp. 1682-1704, 2016. https://doi.org/10.1016/j.apenergy.2016.09.043

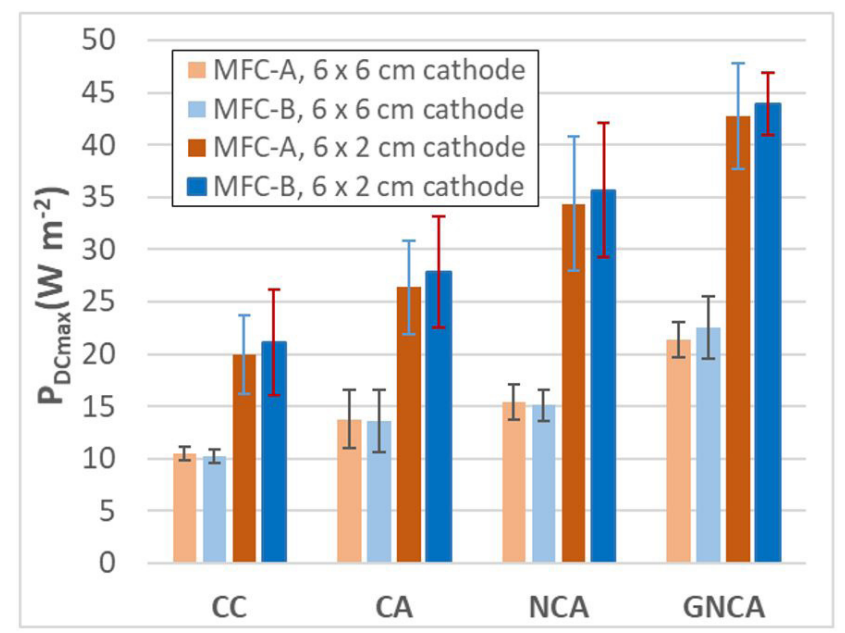

Fig. 4 Maximum power density values normalized to cathode geometric surface in MFC-A and MFC-B with the two different cathode size

metal free alternative cathode catalyst for MFC technologies. Based on the results, future research should focus on the optimization of average pore size and pore size distribution to exploit the full potential of this novel carbonaceous material.

\section{Acknowledgements}

The research was supported by the Higher Education Excellence Program (FIKP) of the Ministry of Human Capacities (EMMI) within the frame of Biotechnology research area at Budapest University of Technology and Economics (BME FIKP-BIO) and by the ÚNKP-20-3 New National Excellence Program of the Ministry for Innovation and Technology. The valuable work of Hanna Sadeczky is highly acknowledged.

[5] Alipanahi, R., Rahimnejad, M., Najafpour, G. "Improvement of sediment microbial fuel cell performances by design and application of power management systems", International Journal of Hydrogen Energy, 44(31), pp. 16965-16975, 2019.

https://doi.org/10.1016/j.ijhydene.2019.04.162

[6] Singh, H. M., Pathak, A. K., Chopra, K., Tyagi, V. V, Anand, S., Kothari, R. "Microbial fuel cells: a sustainable solution for bioelectricity generation and wastewater treatment", Biofuels, 10(1), pp. 11-31, 2019.

https://doi.org/10.1080/17597269.2017.1413860

[7] Lóránt, B., Gyalai-Korpos, M., Goryanin, I., Tardy, G. M. "Application of Air Cathode Microbial Fuel Cells for Energy Efficient Treatment of Dairy Wastewater", Periodica Polytechnica Chemical Engineering, 65(2), pp. 200-209, 2021. https://doi.org/10.3311/PPch.16695

[8] Cui, Y., Lai, B., Tang, X. "Microbial Fuel Cell-Based Biosensors", Biosensors, 9(3), Article number: 92, 2019. https://doi.org/10.3390/bios9030092 
[9] Tardy, G. M., Lóránt, B., Gyalai-Korpos, M., Bakos, V., Simpson, D., Goryanin, I. "Microbial fuel cell biosensor for the determination of biochemical oxygen demand of wastewater samples containing readily and slowly biodegradable organics", Biotechnology Letters, 43(2), pp. 445-454, 2021. https://doi.org/10.1007/s10529-020-03050-5

[10] Lóránt, B., Gyalai-Korpos, M., Goryanin, I., Tardy, G. M. "Single chamber air-cathode microbial fuel cells as biosensors for determination of biodegradable organics", Biotechnology Letters, 41(4-5), pp. 555-563, 2019. https://doi.org/10.1007/s10529-019-02668-4

[11] Cheng, S., Liu, H., Logan, B. E. "Power Densities Using Different Cathode Catalysts ( $\mathrm{Pt}$ and CoTMPP) and Polymer Binders (Nafion and PTFE) in Single Chamber Microbial Fuel Cells", Environmental Science \& Technology, 40(1), pp. 364-369, 2006. https://doi.org/10.1021/es0512071

[12] Oh, S. E., Min, B., Logan, B. E. "Cathode Performance as a Factor in Electricity Generation in Microbial Fuel Cells", Environmental Science \& Technology, 38(18), pp. 4900-4904, 2004. https://doi.org/10.1021/es049422p

[13] Tang, C., Zhang, Q. "Nanocarbon for Oxygen Reduction Electrocatalysis: Dopants, Edges, and Defects", Advanced Materials, 29(13), Article number: 1604103, 2017. https://doi.org/10.1002/adma.201604103

[14] Xiong, D., Li, X., Fan, L., Bai, Z. "Three-Dimensional Heteroatom-Doped Nanocarbon for Metal-Free Oxygen Reduction Electrocatalysis: A Review", Catalysts, 8(8), Article number: 301, 2018.

https://doi.org/10.3390/catal8080301

[15] Tardy, G. M., Lóránt, B., Lóka, M., Nagy, B., László, K. "Enhancing substrate utilization and power production of a microbial fuel cell with nitrogen-doped carbon aerogel as cathode catalyst", Biotechnology Letters, 39(7), pp. 993-999, 2017. https://doi.org/10.1007/s10529-017-2338-X

[16] Yang, W., Peng, Y., Zhang, Y., Lu, J. E., Li, J., Chen, S. "Air Cathode Catalysts of Microbial Fuel Cell by Nitrogen-Doped Carbon Aerogels", ACS Sustainable Chemistry \& Engineering, 7(4), pp. 3917-3924, 2019. https://doi.org/10.1021/acssuschemeng.8b05000

[17] Zhang, X., He, W., Zhang, R., Wang, Q., Liang, P., Huang, X., Logan, B. E., Fellinger, T. P. "High-Performance Carbon Aerogel Air Cathodes for Microbial Fuel Cells", ChemSusChem, 9(19), pp. 2788-2795, 2016.

https://doi.org/10.1002/cssc.201600590

[18] Tian, X., Zhou, M., Tan, C., Li, M., Liang, L., Li, K., Su, P. "KOH activated $\mathrm{N}$-doped novel carbon aerogel as efficient metal-free oxygen reduction catalyst for microbial fuel cells", Chemical Engineering Journal, 348, pp. 775-785, 2018. https://doi.org/10.1016/j.cej.2018.05.007

[19] Yang, W., Chata, G., Zhang, Y., Peng, Y., Lu, J. E., Wang, N., Mercado, R., Li, J., Chen, S. "Graphene oxide-supported zinc cobalt oxides as effective cathode catalysts for microbial fuel cell: High catalytic activity and inhibition of biofilm formation", Nano Energy, 57, pp. 811-819, 2019.

https://doi.org/10.1016/j.nanoen.2018.12.089
[20] Li, M., Zhou, S., Xu, M. "Graphene oxide supported magnesium oxide as an efficient cathode catalyst for power generation and wastewater treatment in single chamber microbial fuel cells", Chemical Engineering Journal, 328, pp. 106-116, 2017. https://doi.org/10.1016/j.cej.2017.07.031

[21] Nagy, B., Bakos, I., Bertóti, I., Domán, A., Menyhárd, A., Mohai, M., László, K. "Synergism of nitrogen and reduced graphene in the electrocatalytic behavior of resorcinol - Formaldehyde based carbon aerogels", Carbon, 139, pp. 872-879, 2018. https://doi.org/10.1016/j.carbon.2018.07.061

[22] Nagy, B., Domán, A., Menyhárd, A., László, K. "Influence of Graphene Oxide Incorporation on Resorcinol-Formaldehyde Polymer and Carbon Aerogels", Periodica Polytechnica Chemical Engineering, 62(4), pp. 441-449, 2018. https://doi.org/10.3311/PPch.12915

[23] Lóránt, B., Lóka, M., Tardy, G. M. "Substrate concentration dependency of electricity production in microbial fuel cells", In: The 5th International Youth Conference on Energy (IYCE), Pisa, Italy, 2015, pp. 1-7. https://doi.org/10.1109/IYCE.2015.7180786

[24] Lin, C., Ritter, J. A. "Effect of synthesis pH on the structure of carbon xerogels", Carbon, 35(9), pp. 1271-1278, 1997. https://doi.org/10.1016/S0008-6223(97)00069-9

[25] Czakkel, O., Marthi, K., Geissler, E., László, K. "Influence of drying on the morphology of resorcinol-formaldehyde-based carbon gels", Microporous and Mesoporous Materials, 86(1-3), pp. 124-133, 2005. https://doi.org/10.1016/j.micromeso.2005.07.021

[26] Brunauer, S., Emmett, P. H., Teller, E. "Adsorption of Gases in Multimolecular Layers", Journal of the American Chemical Society, 60(2), pp. 309-319, 1938. https://doi.org/10.1021/ja01269a023

[27] Dubinin, M. M., Radushkevich, L.V. "The Equation of the Characteristic Curve of Activated Charcoal", Proceedings of the Union of Soviet Socialist Republics Academy of Sciences: Chemical Section, 55, pp. 331-333, 1947.

[28] Landers, J., Gor, G. Y., Neimark, A. V. "Density functional theory methods for characterization of porous materials", Colloids and Surfaces A: Physicochemical and Engineering Aspects, 437, pp. 3-32, 2013. https://doi.org/10.1016/j.colsurfa.2013.01.007

[29] Tardy, G. M., Lóránt, B., Lóka, M. "Substrate concentration dependence of voltage and power production characteristics in two-chambered mediator-less microbial fuel cells with acetate and peptone substrates", Biotechnology Letters, 39(3), pp. 383-389, 2017. https://doi.org/10.1007/s10529-016-2256-3

[30] Oh, S. E., Logan, B. E. "Proton exchange membrane and electrode surface areas as factors that affect power generation in microbial fuel cells", Applied Microbiology and Biotechnology, 70(2), pp. 162-169, 2006. https://doi.org/10.1007/s00253-005-0066-y 
[31] Kaneko，K., Otsuka，H. "新しいIUPAC 勧告と気体吸着による ナノ細孔体の細孔構造評価" (New IUPAC recommendation and characterization of nanoporous materials with physical adsorption), Accounts of Materials \& Surface Research, 5(2), pp. 25-32, 2020. [online] Available at: https://www.hyomen.org/ en/wp-content/uploads/papers/vol5_no2/kaneko/kaneko_72.pdf [Accessed: 26 July 2021] (in Japanese)
[32] Nagy, B., Villar-Rodil, S., Tascón, J. M. D., Bakos, I., László, K. "Nitrogen doped mesoporous carbon aerogels and implications for electrocatalytic oxygen reduction reactions", Microporous and Mesoporous Materials, 230, pp. 135-144, 2016.

https://doi.org/10.1016/j.micromeso.2016.05.009 